\title{
Biomimetic Antifreeze Polymers: A Natural Solution to Freeze-Thaw Damage in Cement and Concrete
}

\author{
Mohammad Matar ${ }^{1}$, Shane Frazier ${ }^{2}$ and Wil V. Srubar III $^{3}$ \\ ${ }^{1}$ Department of Civil, Environmental, and Architectural Engineering, University of Colorado Boulder, \\ ECOT 441 UCB 428, Boulder, Colorado 80309 USA, mohammad.matar@colorado.edu \\ ${ }^{2}$ Materials Science and Engineering Program, University of Colorado Boulder, UCB 027, Boulder, \\ Colorado 80303 USA, shane.frazier@colorado.edu \\ ${ }^{3}$ Department of Civil, Environmental, and Architectural Engineering, University of Colorado Boulder, \\ ECOT 441 UCB 428, Boulder, Colorado 80309 USA \\ Materials Science and Engineering Program, University of Colorado Boulder, UCB 027, Boulder, \\ Colorado 80303 USA wsrubar@colorado.edu
}

\begin{abstract}
Ice is one of the few substances on Earth that expands when it freezes. Consequently, this phase change causes damage to porous cementitious materials that absorb water and undergo freezethaw cycling. Inspired by nature, the objective of this work is to characterize biomimetic antifreeze polymers (BAPS) that explicitly mimic the behavior of antifreeze proteins (AFPs) and antifreeze glycoproteins (AFGPS) naturally found in plants, fish, insects, and bacteria for use as a concrete additive. The ultimate goal of this work is to enhance the freeze-thaw durability of ordinary portland cement (OPC) concrete without the use of traditional air entraining agents (AEAs). This work will highlight recent research that has shown that small additions, less than $0.1 \%$ by wt. of cement, of $B A P s$ that exhibit ice recrystallization inhibition (IRI) activity can mitigate freeze-thaw damage in $O P C$ paste and concrete while entraining less than $3 \%$ air.
\end{abstract}

Keywords: Biomimetic Antifreeze Polymer, Freeze-Thaw Durability.

\section{Introduction}

\subsection{Freeze-Thaw Damage}

Concrete exposed to cyclic freezing and thawing temperatures is susceptible to damage. It is commonly accepted that hydraulic, osmotic, and crystallization pressures develop when ice forms in the pore structure of concrete leading to internal micro-cracking (Powers, 1975; Scherer et al., 2005). The internal damage reduces the durability by decreasing overall compressive strength, increasing susceptibility to water and ion ingress, and increasing susceptibility to additional freeze-thaw damage.

\subsection{Mitigation of Freeze-Thaw Damage in Concrete}

The default method used to mitigate freeze-thaw damage in OPC concrete since the 1930s has been through the creation of an entrained air void system via the addition of air entraining agents (AEAs). Research into other methods include super absorbent polymers to create properly sized and spaced voids (Lausten, et al., 2015), supplementary cementitious materials (Sabir, 1997; Duan, et al., 2013) and nanoparticles (Behfarnia, Salemi, 2013; Gonzalez, et al., 2016) for reducing porosity, hydrophobic materials to reduce water ingress (Liu, Hansen, 2016), and polymeric fibers for containment of crack propagation (Nam, et al., 2016). 


\subsubsection{Air entraining agents}

AEAs stabilize air voids during the mixing process through a surfactant mechanism. The air voids provide pressure relief sites and preferred locations for ice formation in hardened concrete. In the field it is commonplace to only measure fresh state air content to predict the effectiveness air entrainment, with prescribed values being 3-7.5\% by volume of concrete (ACI Committee 201, 2016). However, much research has shown that a proper pore size and pore size distribution, spacing factor, and minimum water saturation level $(<86 \%)$ must be met for the air void system to be effective (Li, W, et al., 2012; T. C. Powers, et al. 1954; L. Du, et al., 2005; S. Chatterji, et al., 2003). AEAs can be highly effective when properly used but notable drawbacks include a reduction in mechanical strength, increased permeability, and retardation of set time (X. Chen et al., 2013; H. S. Wong et al., 2011). Additionally, it is difficult in the field to obtain a proper size distribution and spacing factor. Recent research has indicated that even when an air void system is properly created, that after a minimum water saturation level is met damage is inevitable (Li, W et al., 2012).

\subsection{Biomimetic Antifreeze Polymers}

Nature produces antifreeze proteins (AFPs) and antifreeze glycoproteins (AFGPs) to allow a variety of cold climate species to survive. Although AFPs display excellent antifreeze properties, they are currently not an economical option due to limitations in production and they are known to lose Delesky et al. 2019) behavior to AFPs and PVA being the most reduction or even prevention The chemical functionality of PVA mimics the highly hydroxylated carbohydrates of AFGPS.

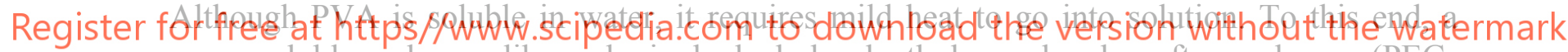
more soluble polymer like polyvinyl alcohol-polyethylene glycol graft copolymer (PEGPVA) is of interest. Recent work (Frazier et al., in review) showed that PEG-PVA displays IRI activity which was expected due to the fact that it is composed of $75 \%$ PVA (E. A. Fouad et al. 2011).

\section{Experimental Methods}

\subsection{Specimen Preparation}

Specimens were prepared using the mix compositions described in Table 1. Specimens were divided into three test groups and labeled according to their PEG-PVA content. One test group, AEA in Table 1, contained a commercially available liquid AEA.

The components of each test group were mixed and poured into cylindrical and prismatic molds. Three 4"x8" cylinders were made for compression testing. Four 3"x3"x16" prisms were made for each test group where three were subjected to freeze-thaw cycles and one kept at ambient conditions for the duration of the freeze-thaw testing. All specimens were stored at room temperature in a vibration-free environment and covered to prevent evaporation of 
water. After 48 hours, specimens were removed from the molds and transferred to a saturated $\mathrm{Ca}(\mathrm{OH})_{2}$ solution for the remainder of the curing process. Water was saturated with calcium hydroxide per ASTM C511 (ASTM 2003) to prevent leaching of calcium hydroxide. Cylindrical specimens were cured for twenty-eight days per ASTM C 192 (ASTM 2006) and prismatic specimens for 14 days per ASTM C 666 (ASTM 2008).

Table 1. Mix compositions used for all analysis.

\begin{tabular}{cccc}
\hline Material (per cubic yard) & Control & Test Group & PEG-PVA \\
\hline Cement (Type I/II) (lb.) & 521 & 521 & AEA \\
\hline Fine aggregate (lb.) & 1011 & 1011 & 521 \\
\hline Coarse aggregate (lb.) & 2040 & 2040 & 2011 \\
\hline Water/cement ratio (\%) & 50 & 50 & 50 \\
\hline PEG-PVA/cement ratio (\%) & 0 & 0.066 & 0 \\
\hline Air entraining agent (mL/100 kg cement) & 0 & 0 & 15 \\
\hline
\end{tabular}

\subsection{Fresh State Concrete Properties}

Slump and fresh state air content of mixed concrete were measured according to ASTM C143 (ASTM 2011) and C231 (ASTM 2010), respectively. The slump test was performed using a slump test set (Humboldt H-3645). Fresh state air content was determined using a concrete air meter (Humboldt H-2783).

2.3 Hardened State Comcrete Properties
The hardened state air content was estimated
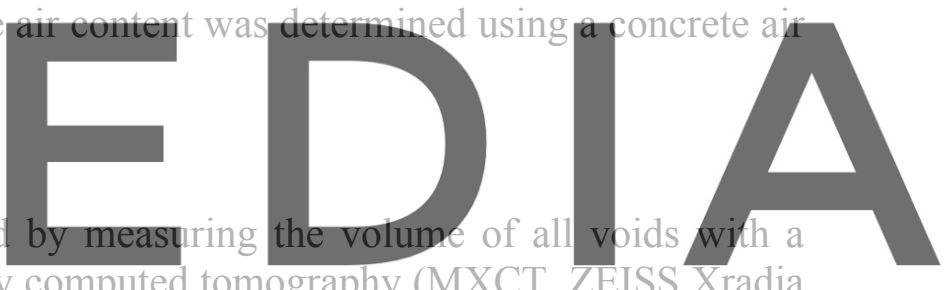

diameter greater than $15 \mu \mathrm{m}$ from micro X-ray computed tomography (MXCT, ZEISS Xradia

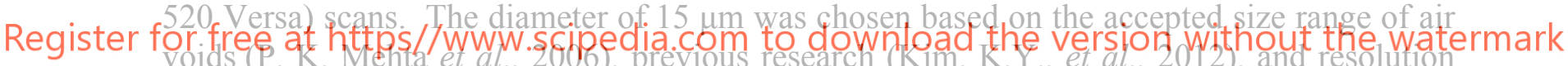
capabilities of MXCT. Cubes with a volume of $\sim 1 \mathrm{in}^{3}$ were cut from samples before exposure to freeze-thaw cycles and used for the scans. The MXCT source voltage was set to $140 \mathrm{kV}$ and the power to $10 \mathrm{~W}$. The source and detector locations were varied to obtain a desired resolution of $\sim 6 \mu \mathrm{m}$. Dragonfly 3.1 software (Object Research Systems) was used to identify voids and calculate their cumulative volume within the scanned volume.

To determine the compressive strength of samples, three cylindrical samples per test group were used in accordance to ASTM C39 (ASTM 2016b). Samples were tested using an ELE International compressive strength testing machine with $10 \mathrm{ksi}$ capacity at a rate of 110 lb./sec.

\subsection{Freeze-Thaw Resistance}

Rapid freeze-thaw cycling was performed according to ASTM C666 Procedure A (ASTM 2008). Three prismatic specimens per test group were tested for 300 cycles. The freezing portion of the cycle had a duration of three hours and reached a minimum of $-18{ }^{\circ} \mathrm{C} \pm 2{ }^{\circ} \mathrm{C}$. The thawing portion of the cycle had a duration of one hours and reached a maximum of $4{ }^{\circ} \mathrm{C}$ $\pm 2{ }^{\circ} \mathrm{C}$. Freeze-thaw resistance was evaluated by measuring the fundamental transverse 
frequency and length change of specimens every 36 cycles for up to 300 cycles. Fundamental transverse frequency was determined using forced resonance method in accordance to ASTM C215 (ASTM 2014). The length change was also measured every 36 cycles for the duration of testing.

\section{Results and Discussion}

\subsection{Fresh State Properties}

Table 2 provides the fresh state air content (\%) and slump (in.) values that were measured at the time of mixing for each test group. Both the slump and fresh state air content increased with the addition of PEG-PVA. It was observed during mixing that the workability improved and concrete was easier to finish with PEG-PVA addition, relative to unmodified concrete. Air bubbles within PEG-PVA modified concrete in the fresh state were visually observed (data not shown) during mixing and finishing processes. It can be concluded that the addition of PEG-PVA entrains some air in the fresh state but less than the AEA dosage used indicating that PEG-PVA has mild surfactant properties. The stability of entrained air in PEG-PVAmodified concrete was investigated in this research and discussed in section 3.2. It is worth noting that the fresh state air content for PEG-PVA modified concrete is less than the 6\% recommended for extreme conditions and a nominal maximum aggregate size of 1 in. per ACI

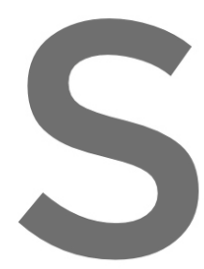
Guide to Durable Concrete (ACI Committee 201,2016).

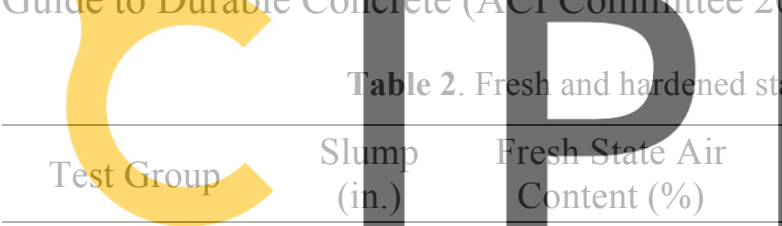
Control 0.375 2.1

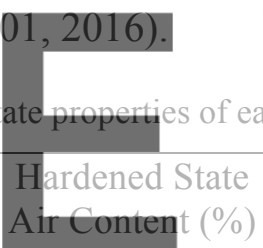

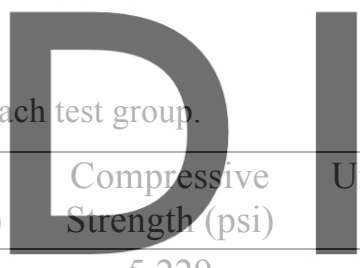

5,229

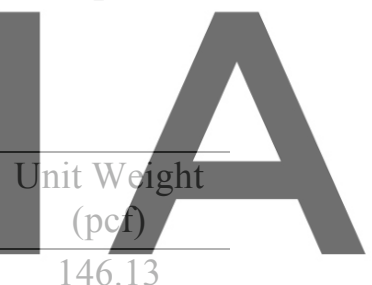

146.13

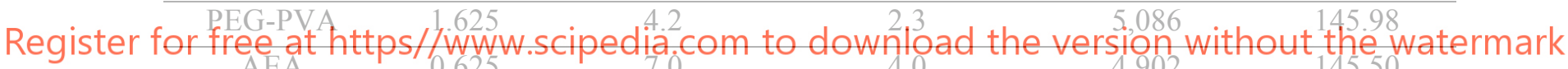
AEA https/6.625.scipedia.

\subsection{Hardened State Properties}

Table 2 presents hardened state properties of samples tested in this research. The air content of PEG-PVA-modified samples decreased from $4.2 \%$ in the fresh state to $2.3 \%$ in the hardened state which indicated that not all air voids generated by the addition PEG-PVA were stable. The reduction further indicates that the polymer only has a mild surfactant effect. In a similar fashion the samples containing air entraining agent saw a reduction in air content of $7.0 \%$ in the fresh state to $4.0 \%$ in the hardened state.

Compressive strength was tested for three 4"x 8 " cylinders per test group after 28 days of curing. The addition of PEG-PVA at an addition $0.066 \%$ by weight of cement was found to slightly reduce the average compressive strength by $2.73 \%$ compared to unmodified concrete. The addition of AEA at $15 \mathrm{~mL}$ per $100 \mathrm{~kg}$ of cement was found to reduce average compressive strength by $6.25 \%$ compared to unmodified concrete. Unit weight at hardened state was found to not be impacted by the addition of PEG-PVA or air entraining agent with reductions of $0.10 \%$ and $0.43 \%$ compared to the unmodified samples respectively. 


\subsection{Freeze-Thaw Resistance}

\subsubsection{Relative dynamic modulus of elasticity}

Three specimens per test group went through freeze and thaw cycles (P1, P2, and P3) while one stayed at room temperature $(\mathrm{P} 4)$ for the duration of testing. Figures 1 shows the relative dynamic modulus of elasticity $\left(\mathrm{P}_{\mathrm{c}}\right)$ with respect to the increasing number of cycles. Also shown is a constant horizontal line at $60 \% \mathrm{P}_{\mathrm{c}}$ which signifies failure as specified by ASTM C666. Figure 1a shows that the value of $\mathrm{P}_{\mathrm{c}}$ for the unmodified specimens started to significantly decrease after around 75 cycles until failure at 125 cycles indicated by a reduction below $60 \%$. As expected, the $\mathrm{P}_{\mathrm{c}}$ for sample $\mathrm{P} 4$ maintained $80-90 \%$ of the initial measurement indicating that the performance of sample P4 has not changed. Figure $1 \mathrm{~b}$ and $1 \mathrm{c}$ show that the behaviour of PEG-PVA and AEA modified both maintain a Pc above $80 \%$ for samples exposed to freeze-thaw cycling (P1-P3) and above $90 \%$ for the sample exposed to ambient conditions (P4). These results indicate excellent freeze-thaw resistance for both PEGPVA and AEA. The fluctuations observed between each data point is likely due to variation in moisture content of each sample.

\subsubsection{Durability factor}

Figure 2a shows the average durability factor for each test group. Durability factor is a measure that indicates the performance of concrete exposed to freeze-thaw conditions. It is a function of the relative freeze-thaw cycles are terminated as specified in were $19.1 \%, 88.6 \%$, an groups respectively. The durability factor of unmodified concrete indicates poor performance, which was visually apparent by the loss of paste and aggregate and general loss of structural

Register for free at https//www.scipedia.com to download the version without the watermark

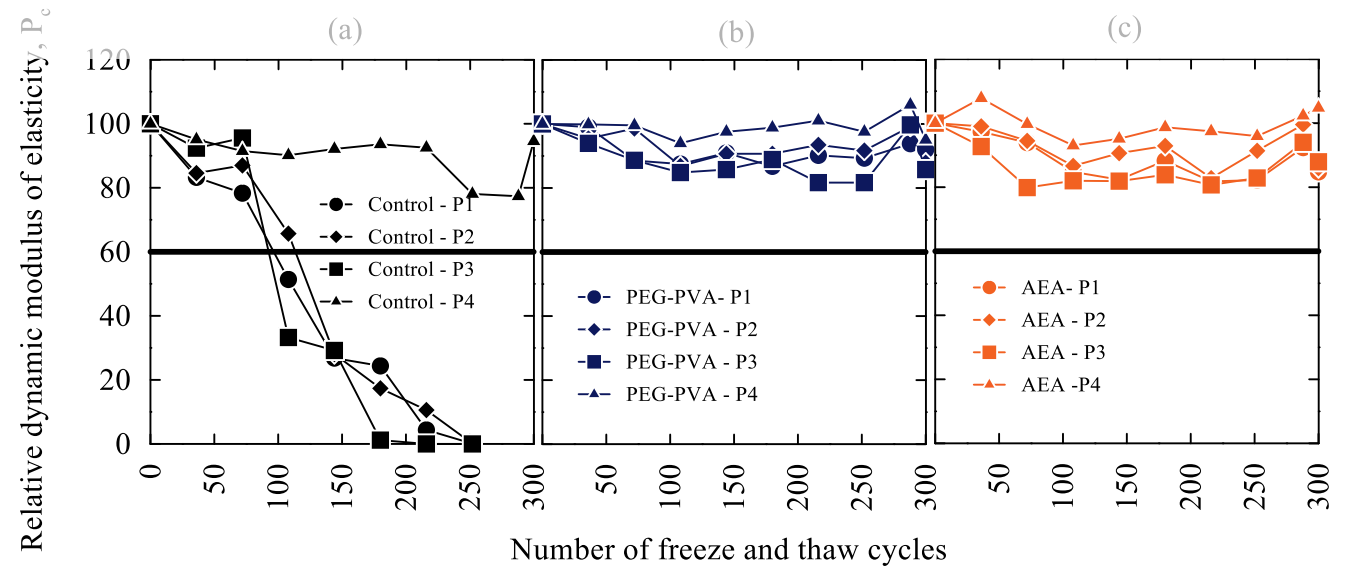

Figure 1. The relative dynamic modulus of elasticity $\left(\mathrm{P}_{c}\right)$ for each test group studied up to 300 freeze-thaw cycles. For each test group, samples P1-P3 were exposed to cyclic freeze-thaw temperature while P4 was kept at ambient temperature for the duration of testing. (a) 0\% PEG-PVA/cement ratio addition (Control). (b) 0.066\% PEG-PVA/cement ratio addition (PEG-PVA). (c) Air entraining agent addition (AEA). The line at $\mathrm{P}_{\mathrm{c}}$ equal to $60 \%$ represents failure. 
integrity of specimens with each subsequent set of cycles. On the other hand, durability factor values for $0.066 \%$ PEG-PVA and AEA modified concrete indicate excellent performance, which was also visually observed.

\subsubsection{Length change}

Measurement of length change during freeze-thaw cycling is described in ASTM C666 as an optional measurement to indicate performance. A length change of $0.1 \%$ maybe used as a trigger to stop freeze-thaw cycles and terminate testing. The greater the length change in concrete the more degradation it has experienced and the lower the performance. Figure $2 \mathrm{~b}$ shows the change in length with increasing number of cycles. The figure indicates that unmodified samples experienced large expansion at the time of failure. $0.066 \%$ PEG-PVA and AEA modified samples experienced significantly less length change, less than $0.1 \%$. According to ASTM C666 the unmodified concrete samples have failed while modified samples have passed.

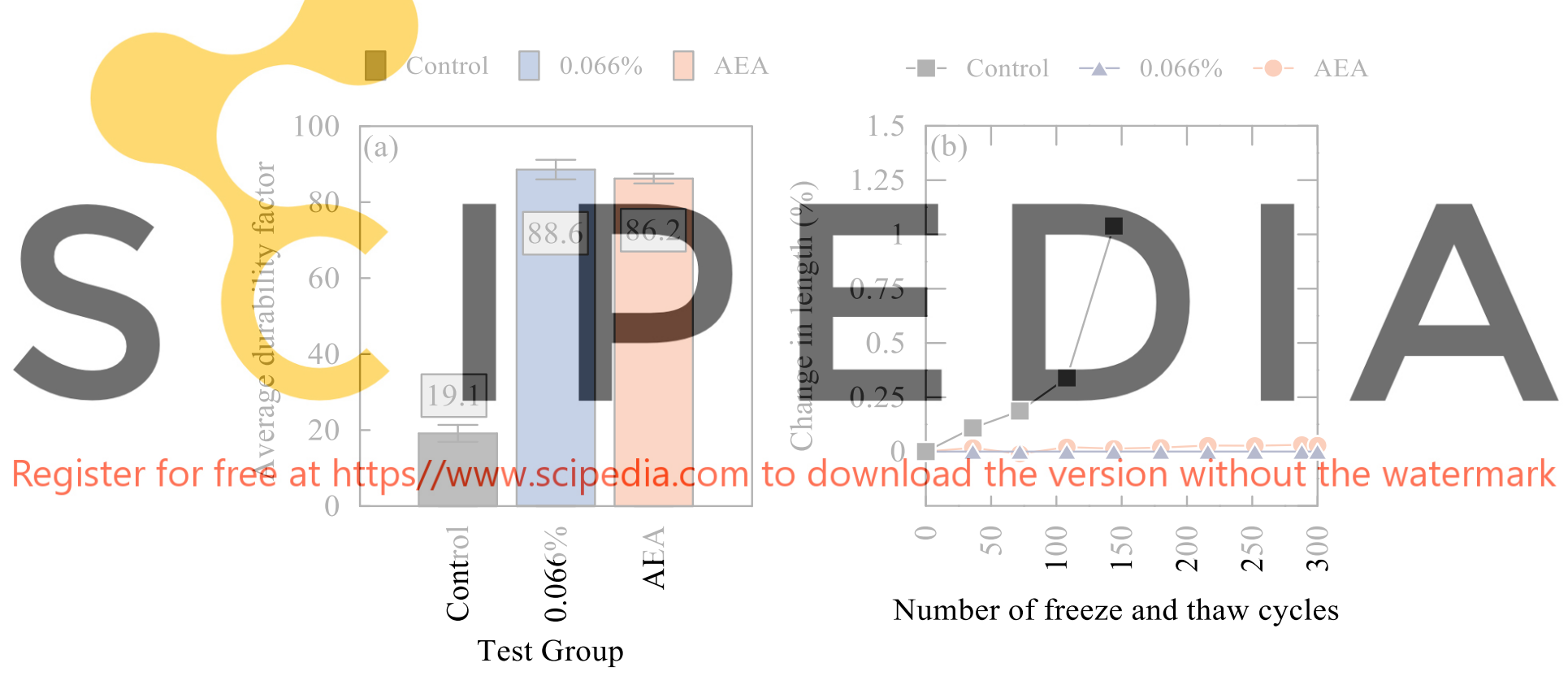

Figure 2. (a) Average durability factor for each test group. Error bars indicate standard deviation for $n=3$. (b) Average length change for each test group up to 300 freeze-thaw cycles. Average for $n=3$ samples per test group.

\section{Conclusions}

PEG-PVA was found to be as effective as a commercially available AEA at mitigating freezethaw damage while entraining minimal air. The addition of PEG-PVA was found to increase fresh state air content and slump compared to unmodified concrete. Although the fresh state air content increased with the addition of PEG-PVA, micro X-ray computed tomography has shown that hardened state air content was less than that of unmodified concrete, $2.3 \%$ for PEG-PVA addition. We can conclude that air entrained in the fresh state due to PEG-PVA addition is not stable and the air voids collapse during concrete consolidation and hardening. PEG-PVA-modified and AEA samples were proven to improve freeze and thaw resistance as 
indicated by relative dynamic modulus (greater than $80 \%$ ), durability factor (greater than $85 \%$ ), and length change (less than $0.1 \%$ ). Addition of PEG-PVA at a concentration of $0.066 \%$ was found to have no influence on compressive strength compared to AEA which experienced a $6.25 \%$ reduction.

\section{ORCID}

Wil Srubar: http://orcid.org/0000-0001-8226-2458

\section{References}

ACI Committee 201, Guide to Durable Concrete (American Concrete Institute, 2016)

ASTM. (2003). "Standard Specification for Mixing Rooms, Moist Cabinets, Moist Rooms, and Water Storage Tanks Used in the Testing of Hydraulic Cements and Concretes." Standard C511, ASTM International, West Conshohocken, PA.

ASTM. (2006). "Standard practice for making and curing concrete test specimens in the laboratory." Standard C192, ASTM International, West Conshohocken, PA.

ASTM. (2008). "Test method for resistance of concrete to rapid freezing and thawing." Standard C666, ASTM International, West Conshohocken, PA

ASTM. (2010). "Standard Test Method for Air Content of Freshly Mixed Concrete by the Pressure Method." Standard C231, ASTM International, West Conshohocken, PA.

ASTM. (2011). "Slump of Hydraulic Cement Concrete." Standard C143, ASTM International, West Conshohocken, PA.

ASTM. (2014). "Standard test method for fundamental transyerse longitudinal, and torsional resonant frequencies of concret st

ASTM. (2016). "Standard te ASTM C39, ASTM Int

Behfarnia, K. and Salemi. concrete. Constr. Build

Chatterji, S. (2003). Fredzing of agents. Cem. Concr. Compos. 25, 759-765

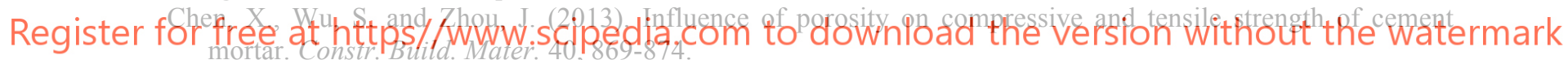

Congdon, T. Notman, R. and Gibson, M.I. (2013). Antifreeze (Glyco)protein Mimetic Behavior of Poly(vinyl alcoho1): Detailed Structure Ice Recrystallization Inhibition Activity Study. Biomacromolecules 14, 15781586.

Delesky, E.A., Frazier, S.D., Wallat, J.D., Bannister, K.L., Heveran, C.M. and Srubar III, W.V. (2019). IceBinding Protein from Shewanella frigidimarinas Inhibits Ice Crystal Growth in Highly Alkaline Solutions. Polymers 11, 299.

Du, L. and Folliard, K.J. (2015) Mechanisms of air entrainment in concrete. Cem. Concr. Res. 35, 1463-1471.

Duan, P., Shui, Z., Chen, W. and Shen, C. (2013). Enhancing microstructure and durability of concrete from ground granulated blast furnace slag and metakaolin as cement replacement materials. J. Mater. Res. Technol., 2(1), 52-59.

Fouad, E.A., El-Badry, M., Neau, S.H., Alanazi, F.K. and Alsarra, I.A. (2011). Technology evaluation: Kollicoat IR. Expert Opin. Drug Deliv. 8, 693-703.

Frazier, S. D., Matar, M. G., Osio-Norgaard, J., Aday, A. N., Delesky, E. A. and Srubar III, W. V. (2020). Inhibiting Freeze-Thaw Damage in Cement Paste and Concrete by Mimicking Nature's Antifreeze. Cell Reports Physical Science, 100060.

Gonzalez, M., Tighe, S. L., Hui, K., Rahman, S. and Lima, A. O. (2016). Evaluation of freeze/thaw and scaling response of nanoconcrete for Portland Cement Concrete (PCC) pavements. Constr. Build. Mater., 120(1), 465-472.

Laustsen, S.; Hasholt, M. T. and Jensen, O. M. (2015). Void Structure of Concrete with Superabsorbent Polymers and Its Relation to Frost Resistance of Concrete. Mater. Struct., 48(1-2), 357-368. 
Li, W., Pour-Ghaz, M., Castro, J. and Weiss, J. (2012). Water Absorption and Critical Degree of Saturation Relating to Freeze-Thaw Damage in Concrete Pavement Joints. J. Mater. Civil Eng., 24(3), 299-307.

Mehta, P.K. and Monteiro, P.J.M. Concrete: Microstructure, Properties, and Materials (McGraw-Hill, 2006).

Powers, T.C. (1954). Void Spacing as a Basis for Producing Air-Entrained Concrete. J. Am. Concr. Inst. 25, 741-760.

Powers, T. C. (1975). Freezing Effects in Concrete. In: Durability of concrete, American Concrete Institute, Special Publication 47, 1-12.

Sabir, B. B. (1997). Mechanical properties and frost resistance of silica fume concrete. Cem. Concr. Compos., 19(4), 285-294.

Scherer, G. W. and Valenza, J. J. (2005). Mechanism of frost damage. Mater. Sci. of Concr. (VII), 7, 209-246.

Wong, H.S., A. M. Pappas, A.M., Zimmerman, R.W., and Buenfeld, N.R. (2011). Effect of entrained air voids on the microstructure and mass transport properties of concrete. Cem. Concr. Res. 41, 1067-1077.
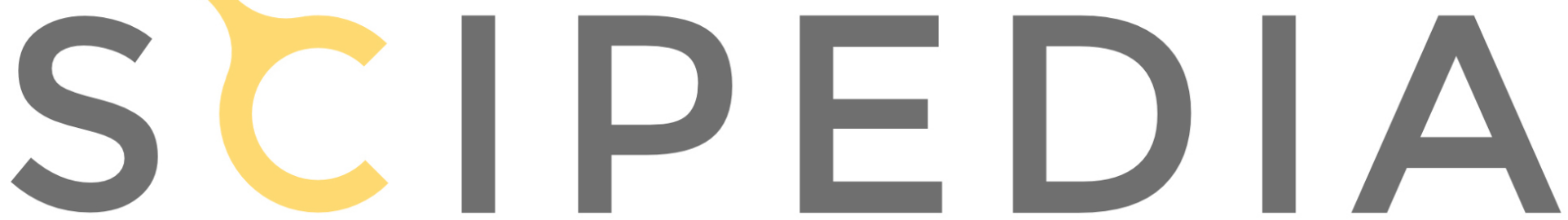

Register for free at https//www.scipedia.com to download the version without the watermark 